\title{
The Role of the Orthodontist during the Management of Patient with the Lip and Palatale Cleft
}

\section{Saif $\mathrm{S}^{*}$ and Bourzgui F \\ Department of Orthodontics, University of Hassan II, Morocco}

*Corresponding author: Sarah Saif, Resident, Department of Orthodontics, Faculty of Dentistry, University of Hassan II, Casablanca, Post box No:20120, Morocco, Tel :212660363744; Email: drsarahasaif@gmail.com

\section{Research Article}

Volume 4 Issue 2

Received Date: April 16, 2019

Published Date: June 04, 2019

DOI: 10.23880 /oajds- 16000230

\section{Abstract}

Objective: was the aim of this study was to assess cleft lip and /or palate (CL/P) patient's management strategies, to determine the role of the orthodontist during primary and secondary treatment, to highlight the treatment needs of patients with cleft palates and to develop a management protocol suitable for these patients in order to reduce the sequelae.

Materials and Methods: Through a cross-sectional descriptive study within the dento- facial orthopedic department of the dental consultation and treatment center of Casablanca, 120 patients with labio-alveolo-palato-velar clefts were interviewed and examined. A six page questionnaire was designed to collect the information needed for this study.

Results: $51,7 \%$ of the patients were males and 48,3\% were females, primary surgery was generally done during the first months after birth, the lip and nose repair at the age of 6 months, the uranoplasty and veloplasty at the age of 12 months, bone grafting surgery was mainly done in patients between 5 and 11 years old .Orthodontic treatment was started in mixed dentition. Treatment of nasal, labial, and phonatory sequelea were provided later in life.

Conclusion: The management of patients with CLP is still poor and needs further investigation in order to gain insight into persisting problems and needs

Keywords: Orthodontists; Cleft Lip-Palate, Nonsyndromic; Managed Care Programs; Morocco

\section{Abbreviations: CL: Cleft Lip; CP: Cleft Palate.}

\section{Introduction}

Cleft lip and/or palate (CL/P) are congenital oro-facial embryonic anomalies of development that may affect either the soft tissues: the lip, the ala of the nose, or the hard tissues: the alveolar ridge, and / or the palate. These isolated lesions are often associated with each other. These defects are among the most common and most impressive congenital abnormalities [1].

The birth prevalence of $\mathrm{CL} \pm \mathrm{CP}$ has been reported to be between 1 in 700 and 1 in 1000 live births, whereas for cleft palate (CP) it is about 1 in 2000 live births worldwide. Genetic studies on human samples have 


\section{Open Access Journal of Dental Sciences}

demonstrated that $\mathrm{CL} / \mathrm{P}$ has an heterogeneous genetic background, and environmental factors that contribute in the development of this malformation [1,2]. Its pathogenesis occurs early during embryonic development and is presumed to be the outcome from the failure of fusion of the various facial process [3] which causes many functional repercussions that affect speech, breathing, eating, appearance and psychology, ...), therefore these defects require a long and heavy multidisciplinary management, with noticeable results in the long term since the treatment takes almost twenty years.

Medical care for patients with CL/P starts from birth, it is provided by a multidisciplinary team of specialists such as maxillofacial surgeons, pedodontists, orthodontists, otolaryngologists, speech therapists and psychologists. This multidisciplinary team intervene regularly throughout the treatment, evaluating together the results obtained. Their goal here is more than to cure but to give the child a new aptitude to live.

Moreover, the orthodontist plays an integral role in this team. He participates in the treatment of the patient from his first days by making a palatal appliance, then the orthopedic and orthodontic treatment in temporary and/or mixed dentition that will eventually be continued through adolescence and adulthood. $\mathrm{He}$ is often confronted with compromising the goals of orthodontic treatment and the quality of the results obtained [4].

The aims of our study were: to evaluate the management of patients with facial clefts, to determine the role of the orthodontist during primary and secondary treatment (i.e., from birth to adulthood), to highlight the treatment and care needs of patients with clefts and to develop an appropriate management protocol for these patients in order to minimize the effects of these abnormalities on their lives.

\section{Patients and Method}

We conducted a descriptive cross-sectional epidemiological survey within the dento-facial orthopedic department of the dental consultation and treatment center of Casablanca. Were included in our sample, patients with labio-alveolo-palato-velar clefts. Patients of all ages seen and treated in this structure mentioned above. Excluded from our sample were patients with facial clefts that did not affect the oral cavity. Our study involved 120 patients consecutively enrolled with CLP.
A six-page questionnaire containing seven sections was designed to collect the information needed for our study and was organized as follows:

a) Patient identification.

b) The types of clefts, their classification and the malformations associated.

c) Primary surgeries and early orthopedics.

d) Speech therapy.

e) The bone rehabilitation of the alveolar cleft.

f) Proper orthodontic treatment.

g) The treatment of secondary squeal.

A pretest was carried out on patients with clefts which aimed to help the investigator become familiar with the variables used in the survey, to determine the subsequent difficulties during the investigation and to estimate the time required to complete the survey.

Our survey was divided into three stages for each patient: Verification of the inclusion criteria, the interview and the oral examination. Furthermore, by consulting the medical records of the examined patients, we were able to complete information about surgeries and the age of completion of these interventions.

This survey took approximately 5 months from September 2011 to February 2012, the data collected from the interviews and the clinical examination were reported on the survey sheet.

Data analysis was performed using Epi info 6 Fr. at the Laboratory of Epidemiology at the Dental school Casablanca. This study was approved by the ethical review board of the Faculty of Dentistry, University Hassan II Casablanca, Morocco.

\section{Results}

The age of sample varied between 3 months and 36 years with a mean of 4,41 years ...., divided into four intervals : $25 \%$ Were aged between 0 and 5 years, $25 \%$ were aged between 6 and 12 years , 25\% between 13 and 17 years and another $25 \%$ from 18 years and above. Up to $51,7 \%$ of our sample were males and $48,3 \%$ were females. The sample was divided according to the socio economic level: The results showed that $85,8 \%$ of the respondents had a low socio economic level, $11,7 \%$ had an average socio economic level and only $2,5 \%$ had a superior socio- economic level (Table 1). 
Open Access Journal of Dental Sciences

\begin{tabular}{|c|c|c|}
\hline & patients $(\mathbf{n = 1 2 0})$ & Prevalence \\
\hline & $\mathbf{n}$ & 25 \\
\hline Intervals of age & 30 & 25 \\
\hline$[0-5$ years] & 30 & 25 \\
\hline$[6-12$ years] & 30 & 25 \\
\hline$[13-17$ years $]$ & 30 & 48,3 \\
\hline$[+18$ years] & 58 & 51,7 \\
\hline Gender & 62 & 85,8 \\
\hline Female & & 11,7 \\
\hline Male & 103 & 2,5 \\
\hline Socio economic level of the patients & 14 & 100 \\
\hline low & 3 & \\
\hline Average & 120 & \\
\hline High & & \multicolumn{2}{|c|}{} \\
\hline Total & & \\
\hline
\end{tabular}

Table 1: The identification of the population of the study.

Distribution according to the structures affected by the cleft: The results showed $16,7 \%$ of the cases with labio-alveolar clefts, $4.2 \%$ cases with palato-velar clefts, and $79.2 \%$ cases with complete clefts. These results were established according to VEAU classification (Figure 1), which showed $2 \%$ of simple division of the veil, $3 \%$ of palato-velar cleft, $51 \%$ of unilateral labio-alveolo-palatovelar (ULPC) clefts $51 \%$ and $44 \%$ of bilateral labioalveolo-palato-velar clefts (BLPC).

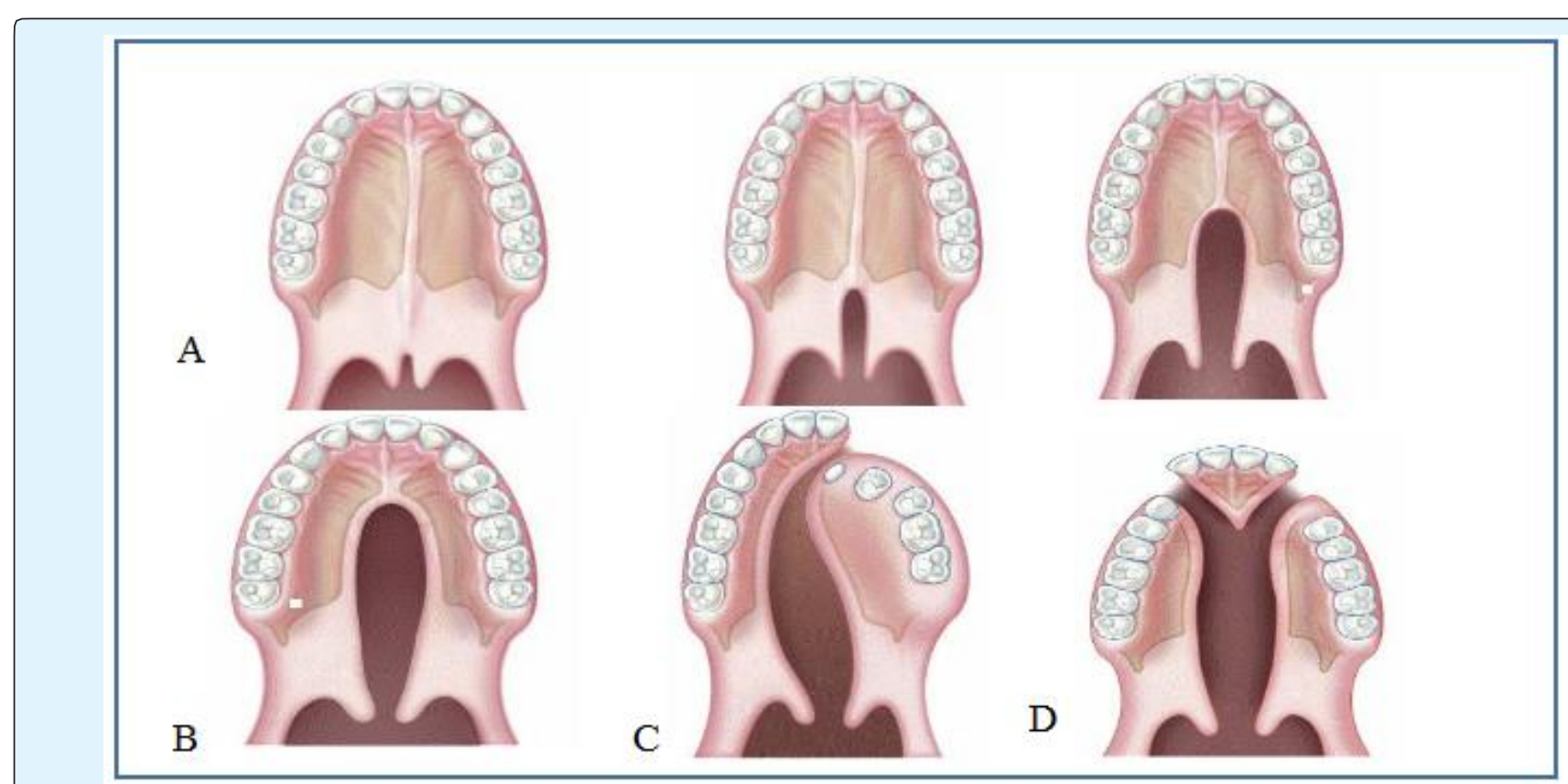

Figure 1: Veau classification: A-VEAU I: defects of the soft palate only, B-VEAU II: defects involving the soft and hard palate, C-VEAU III: defects involving the soft palate to the alveolus usually affecting the lip, D-VEAU IV: complete bilateral cleft.

Distribution according to the affected side, $70,6 \%$ of the patients were affected in the left side, and $29,4 \%$ on the right side. The labio alveolar clefts affected the left side in $45 \%$ of the cases, the right side in $35 \%$ of the cases, and $20 \%$ of the cases had bilateral labio aveloar clefts (Table 2). 


\section{Open Access Journal of Dental Sciences}

\begin{tabular}{|c|c|c|}
\hline Structures affected by the cleft & Numbers & $\mathbf{\%}$ \\
\hline Labio-alveolar & 20 & $16,7 \%$ \\
\hline Palato-velar & 5 & $4,2 \%$ \\
\hline Labio-alvéolo-palato-velar & 95 & $79,1 \%$ \\
\hline Total & 120 & $100 \%$ \\
\hline Distribution according to VEAU classification & & \\
\hline Simple division of the veil & 2 & $2 \%$ \\
\hline Palato-velar cleft & 3 & $3 \%$ \\
\hline Unilateral labio-alveolo-palato-velar clefts & 51 & $51 \%$ \\
\hline Bilateral labio-alveolo-palato-velar clefts & 44 & $44 \%$ \\
\hline Total & 100 & $100 \%$ \\
\hline Distribution according to the affected side & & \\
\hline Left side & 36 & $70,6 \%$ \\
\hline Right side & 15 & $29,4 \%$ \\
\hline Total & 51 & $100 \%$ \\
\hline
\end{tabular}

Table 2: Results related to clefts.

Results related to anomalies associated with clefts $91.7 \%$ of the cases with no associated congenital malformations, $8.3 \%$ of the cases with congenital malformations associated with the clefts including 1 case of left anophthalmia, 1 case of congenital hip dislocation of the hip, 2 cases of congenital eyelid palsy, 2 cases of congenital eye problems, 2 cases of deafness and mute, 2 cases of dwarfism. $61.7 \%$ of the patients presented number abnormalities, $57.5 \%$ presented anomalies of position, $28.3 \%$ presented anomalies of morphology and $25 \%$ presented structure abnormalities (Table 3 ).

\begin{tabular}{|c|c|c|}
\hline Congenital abnormalities & Numbers & Prevalence (\%) \\
\hline Yes & 10 & 8,3 \\
\hline No & 110 & 91,7 \\
\hline Total & 120 & 100 \\
\hline Dental abnormalities & & \\
\hline Number anomalies & 74 & 61,7 \\
\hline Position anomalies & 69 & 57,5 \\
\hline Anomalies of morphology & 34 & 28,3 \\
\hline Structure anomalies & 30 & 25 \\
\hline Total & 100 & 100 \\
\hline
\end{tabular}

Table 3: Results related to anomalies associated with clefts.

\section{Results Related To the Primary Treatment of the Clefts (Figure 2)}

Primary cheiloplasty (lip repair): $94.8 \%$ of the patients underwent primary cheiloplasty, among these patients $64.5 \%$ received the cheiloplasty between 1 and 6 months, between 7 and 12 months for $28.2 \%$ of the patients, and between 16 to 3 years for $7.3 \%$ of the patients $(7,827+/$ $4,988)$.

Primary rhinoplasty: $77.5 \%$ of our sample has performed primary rhinoplasty, at the age of 2-6 months for $60.2 \%$ of the patients, 7 to 12 months for $31.2 \%$, and 16 to 3 years for $8.6 \%$, (sd $8,376+/-5,720)$
Primary veloplasty: $67.5 \%$ of the cases received a veloplasty, with $58.02 \%$ between 5 and 12 months, 33.3 $\%$ between 15 months and 2 years, $8.6 \%$ between 3 and 6 years. $(17,457+/-12,856)$

Primary uranoplasty: $63.3 \%$ of the cases had undergone a uranoplasty, between 5 and 12 months for $40.8 \%, 13$ and 16 months for $9.2 \%, 4$ and 8 years for $7.8 \%(20,632$ $+/-15,127)$

Primary pharyngoplasty: $1.7 \%$ of the patients received a pharyngoplasty, respectively at the age of 15 years and 25 years. 

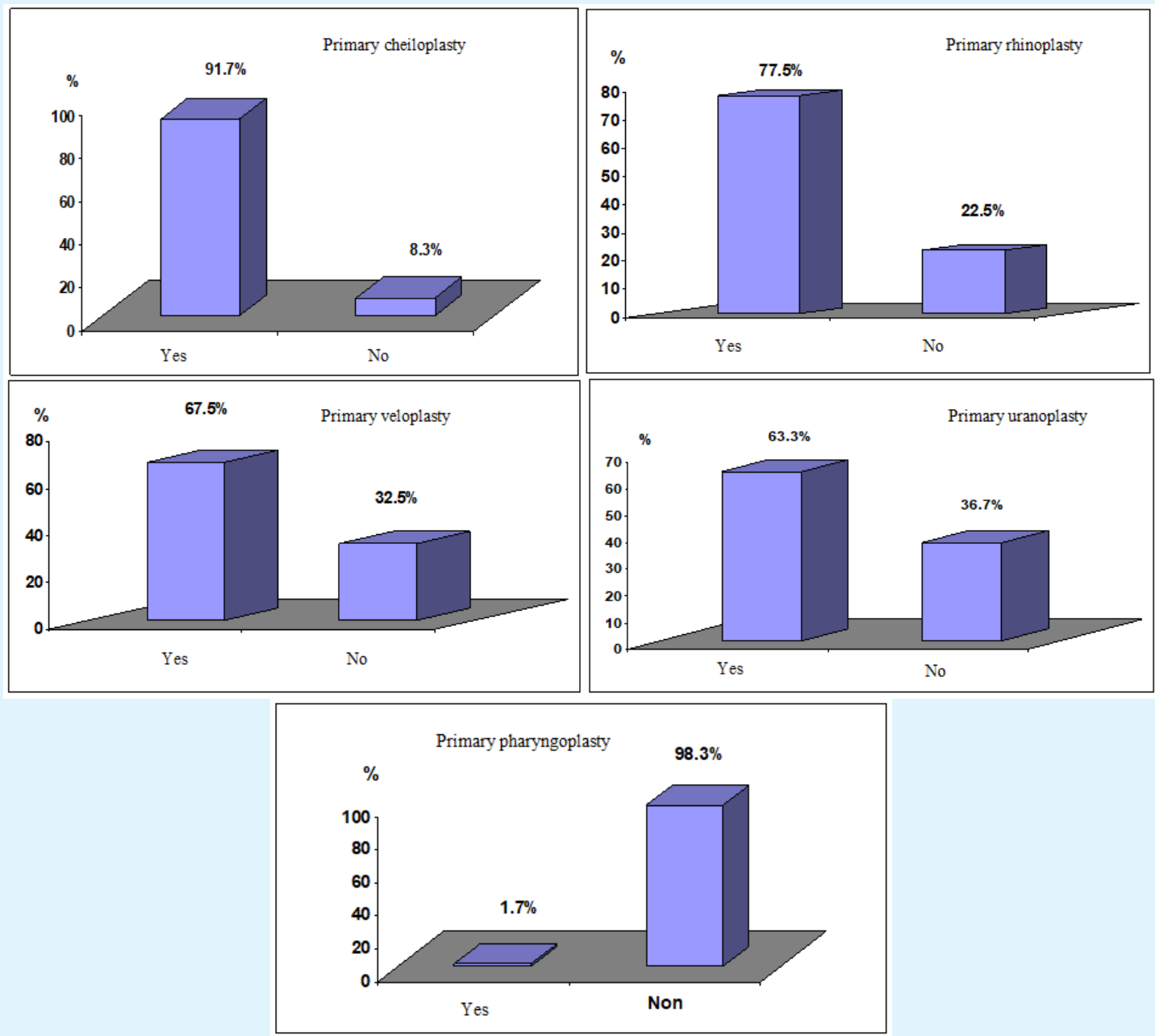

Figure 2: Results related to the primary treatment of clefts

Results related to the bone rehabilitation of the alveolar cleft Table 4 depicts the two techniques used in bone rehabilitation: the bone grafting and gingivoperiosteoplasty, In our sample $22.5 \%$ cases were not old enough to evaluate the completion of a bone graft,
$11.7 \%$ cases performed a bone graft and $65.8 \%$ did not receive a bone graft. $22.5 \%$ of the patients were not old enough to evaluate the completion of a gingivoperiosteoplasty, $4.2 \%$ underwent a gingivoplasty and $73.3 \%$ did not.

\begin{tabular}{|c|c|c|}
\hline Bone graft & $\mathbf{N}$ & $\mathbf{\%}$ \\
\hline Not old enough & 27 & $22,5 \%$ \\
\hline Yes & 14 & $11,7 \%$ \\
\hline No & 79 & $65,8 \%$ \\
\hline Total & 120 & $100 \%$ \\
\hline Gingivo perioplasty & & $22,5 \%$ \\
\hline Not old enough & 27 & $4,2 \%$ \\
\hline yes & 5 & $73,3 \%$ \\
\hline No & 88 & $100 \%$ \\
\hline Total & 120 & \\
\hline
\end{tabular}

Table 4: Results related to the bone rehabilitation of the alveolar cleft. 


\section{Open Access Journal of Dental Sciences}

Speech therapy: $21.7 \%$ were not old enough to assess this variable, $31.7 \%$ received a speech therapy and $46.7 \%$ did not of the 38 cases with speech therapy, the age of intervention varied from 3 years to 36 years: $(11,395+/-$ 7,995) (Table 5).

\begin{tabular}{|c|c|c|}
\hline Speech therapy & N & \% \\
\hline Not old enough & 26 & 21,7 \\
\hline Yes & 38 & 31,7 \\
\hline No & 56 & 46,7 \\
\hline Total & 120 & 100 \\
\hline
\end{tabular}

Table 5: Results related to speech therapy.

\section{Orthopedic and Orthodontic Treatment}

Orthopedic Treatment: $23.3 \%$ of patients who received an appliance at birth (23.3\%) whereas $76.7 \%$ did not have a cleft palate at birth.

Interceptive Treatment: only 1 patient underwent had interceptive treatment in temporary dentition $(0.8 \%)$, $22.5 \%$ of the patients have not yet completed the eruption of temporary teeth and $76.7 \%$ patients did not receive an orthodontic treatment in temporary dentition. Whereas $24.2 \%$ had undergone an interception treatment in mixed dentition, $50 \%$ had no interception treatment in mixed dentition, and the other $25.8 \%$ were in temporary dentition.

Surgical treatment: $43,3 \%$ of the patients are undergoing an ortho-surgical protocol treatment with Management of the effects of the clefts :

Secondary Cheiloplasty: $37.5 \%$ patients are not old enough to assess the possibility of a secondary cheiloplasty, $25 \%$ of the patients underwent performed a secondary cheiloplasty and $37.5 \%$ did not undergo secondary cheiloplasty

Secondary rhinoplasty: $37.5 \%$ were not old enough to evaluate the achievement of a secondary rhinoplasty, rhinoplasty, $15 \%$ were operated and $47.5 \%$ did not undergo secondary rhinoplasty.

Palatoplasty: $37.5 \%$ were not old enough to assess the correction of palatal deformities, $6.7 \%$ had their palatal deformities corrected and $55.8 \%$ did not receive any correction of their deformities.

Management of the phonatory disorder: $37.5 \%$ were not old enough to evaluate this variable, $1.7 \%$ of the patients received speech therapy, $60.8 \%$ patients had no management of the phonatory sequelae.

Distribution of the sample according to the existence or not of psychological therapy: $3.3 \%$ of $\%$ of patients received psychological received psychological therapy whereas $96.7 \%$ did not receive psychological care.

\section{Discussion}

The management of patients with facial clefts, was assessed to determine the role of the orthodontist during primary and secondary treatment (i.e., from birth to adulthood), to highlight the treatment and the care needs of patients with clefts and to develop an appropriate management protocol for these patients in order to minimize the effects of these abnormalities on their lives. This study showed that, $51,7 \%$ of the patients were males and $48,3 \%$ were females, primary surgery was generally done during the first months after birth, the lip and nose repair at the age of 6 months, the uranoplasty and veloplasty at the age of 12 months, bone grafting surgery was mainly done in patients between 5 and 11 years old. Orthodontic treatment was started in mixed dentition. Treatment of nasal, labial, and phonatory sequelea were provided later in life.

In our study, the distribution by sex showed that males were more affected than females, with a percentage of $51.7 \%$. These results are consistent with a study conducted in Kuwait that also showed a high prevalence of the male (54.5\%) compared to female (45.5\%). A study conducted in Madagascar [5], showed a percentage of $51.8 \%$ in males and $48.2 \%$ in females. Another studies in Turkey [6] and showed this high prevalence of males versus females. According to this, males could be more affected by the facial clefts. However, there have been some reports of female preponderance in the literature [7-9].

Our study showed that $85.8 \%$ of the patients with $\mathrm{CL} / \mathrm{P}$ came from a low socio-economic environment level, $11.7 \%$ had an average economical level and only $2.5 \%$ had are of a high socio-economic level. According to Rival \& David [10] the clefts affect all sorts of populations but with variations according to socio-economic status and geographical area. Clefts are thus frequent, in the same country among populations of low socio-economic level. A Californian study by Croen, et al. [11] on Japanese populations living in California showed that the incidence of birth clefts is equivalent to the incidence in Californian populations of European origins. This makes the socioeconomic level a significant factor in the appearance of facial clefts in the population.

The results of our study showed, $16.7 \%$ of labioalveolar clefts, $4.2 \%$ isolated palatal clefts, $79.2 \%$ of unilateral UCLP and bilateral total clefts BCLP, Which 


\section{Open Access Journal of Dental Sciences}

makes the labio-palatal clefts in our study population more frequent followed by the labio-alveolar clefts and isolated palatal clefts. According to the literature, the prevalence of these lesions is different, with the predominance of total labio-palatal clefts. A study conducted in Madagascar [5] showed a high prevalence of total labio-palatal clefts with a percentage of $56.5 \%$ compared to isolated palatal clefts (25.9\%) and lip clefts (17.6\%), another study in Turkey [6] showed a high prevalence of total labio-palatal clefts (91.8\%) and a prevalence of $8.2 \%$ for isolated palatal clefts. Peterson $\mathrm{F}$ [12] estimates the prevalence of labio-palatal clefts at $50 \%$ and $25 \%$ for the labial clefts, and $25 \%$ for palatal clefts. Rival [10] estimates that in France, clefts affect 19.1\%of the population, complete clefts affect $37.2 \%$ of the population and followed by palatal clefts (43.7\%).

In our population, there is a high prevalence of males in UCLP/BCLP, and the opposite for the labio-alveolar clefts and cleft palates. Likewise these results are consistent with those observed in several studies: A study conducted in Kuwait showed a high prevalence of males for total clefts $57.5 \%$ compared to $42.5 \%$ for females. With a high frequency of isolated palatal clefts in females (53\%) compared to males. Another study in Turkey [6] showed found that unilateral and total bilateral clefts were more common in males than females. According to Rival and David [10] gender influences the type and the frequency of clefts. Boys are twice as likely to be affected by total clefts than girls who are, conversely, twice more affected by isolated palatal clefts. Whereas according to Shapira [13], there is no difference between men and women with regard to complete clefts. From this point of view, there may be a male predominance compared to the females in complete clefts and the reverse for the isolated labio-alveolar and palatal clefts.

In the total unilateral clefts and the labio-alveolar clefts, a predominance of the left side is observed: $70.6 \%$ of the total unilateral clefts and $60 \%$ of the pure labioalveolar clefts affected the left side. These results are superimposable to the data of the literature. Lip clefts with or without maxillary-palatal division are 2 times more frequent on the left than on the right side $[10,13]$.

Our study showed that $8.3 \%$ of clefts are associated with isolated congenital malformations: Congenital dislocation of the hip, Anophthalmia, Dwarfism, Deafness and mute, Paralysis of the eyelid muscles. Shapira [13], noted that the frequency of clefts associated with congenital malformations is estimated at $15 \%$ and is increasing. This raise is eventually explained by the decrease of the postnatal mortality around the globe.
The most frequently encountered anomalies were number anomalies (61.7\%), followed by positional anomalies $(57.5 \%)$ and then by anomalies of tooth morphology. In the literature, we find a variable prevalence: A study carried out in Madagascar [5] showed that position anomalies are more frequent $(71.8 \%)$, this predominance of anomalies of position was reported by a Chinese study [14]. Another Jordanian study [15] showed that abnormalities of tooth morphology are the most frequent followed by position and number anomalies which causes more dental abnormalities in patients with clefts than in the healthy population. Number anomalies can occur as agenesis or supernumerary teeth. A study conducted in Brazil [16] revealed a high frequency of agenesis $66.5 \%$, another study in Nigeria [17] revealed $89.5 \%$ of agenesis in lateral incisors. Tan, et al. [18] reported that the maxillary lateral incisor is the most vulnerable to abnormalities maldevelopment, which may explain its high frequency of absence. [18].

Position anomalies were frequent abnormalities in our study (57.5\%). They were most encountered in permanent dentition. Ectopy is the most common position abnormality .The incisor is the most concerned tooth. These results were in agreement with those observed in a study in Nigeria [17] that showed a high prevalence of rotations and dental ectopies. The anomalies of tooth morphology and the anomalies of structure were the least frequent abnormalities in our study with respectively $28.3 \%$ and $25 \%$. Microdontias were the most common abnormalities of shape, most commonly affecting the lateral incisors (91.2\%). Enamel dysplasias were the most common structural abnormalities. All teeth were likely to be affected by this abnormality, central incisors and lateral ones were the most affected. These results differ from those observed in a study in Madagascar [5] that showed a high prevalence of morphology abnormalities $50 \%$. In sum, dental anomalies observed in the facial clefts may concern either temporary or permanent teeth, the two arches, the teeth bordering the clefts and the teeth far from the abnormality. This variability of the abnormalities will probably complicate orthodontic treatment and prolong its duration.

Regarding the primary surgeries of CLP, a wide range of surgical techniques are used for repairing cleft lip and palate, and there is no consensus among surgeons regarding the protocol, timing, and the technique of repair [7]. Primary surgery has a dual purpose, functional rehabilitation and morphological repair of the facial muscle chain. An early intervention is believed to offer a number of advantages: The nasal skin and cartilage of the neonate are soft and malleable, making the correction 


\section{Open Access Journal of Dental Sciences}

easier; postoperative scarring may be minimized; and the psychological and social burden on the baby's family can thus be reduced much earlier [19]. Primary surgery includes lip repair, uranoplasty, staphylorraphy and pharyngoplasty. The goal of cleft lip repair is an anatomic recreation of the normal lip elements with no vertical discrepancy between the affected and normal sides of the central philtral element [20]. In our study, most patients underwent a primary cheiloplasty (91.7\%), at ages ranging from 1 month to 3 years with a high rate at 6 months of age . Lip repair is generally the first intervention performed for cleft closure, the timing of the cheiloplasty was eminently variable from one team to another. It can be done in the first 48 hours after birth until the age of 6 months and can be isolated or in combination with other interventions [4]. In our study $77.5 \%$ underwent a primary rhinoplasty of which $45.2 \%$ performed it at the age of 6 months along with the cleft lip repair. The age of this intervention varies between 2 months and 3 years with a high rate at the age of 6 months. Rhinoplasty consists of the reconstruction of the nostril symmetry, it can be performed at the same time as the lip repair. The only concern with primary rhinoplasty is the disruption of the facial growth by nasal movements [21]. Several theories support a controversial calendar [22]. Complete primary correction, Partial correction, No nasal correction during primary treatment.

The primary veloplasty enables normal growth of the upper jaw and of the facial skeleton in patients with clefts. In his study, Schweckendiek [23], found that the incidence of ear disease diminishes after primary veloplasty. This has been confirmed by others [23]. In our study $67.7 \%$ underwent primary veloplasty. The age of the intervention varies between 5 months and 6 years with a high rate at the age of 12 months (39.5\%). Likewise, Schweckendiek performed veloplasty at the age of 7-8 months 3 weeks before lip repair and reconstruction of the floor of the nose [23].

The ultimate goal of the uranoplasty surgery is to close the communication between the oral and nasal cavities and to reconstruct a functional velum that allows good speech production [7,24]. In our study $63.3 \%$ of the patients performed a palatoplasty. The age of intervention varied between 5 months and 8 years with high rates, respectively, at the age of 12 months (28.9\%) and at the age of 2 years $(26.3 \%)$. In our study, $28.9 \%$ achieved a palatoplasty at the same time as the veloplasty. In the literature, there are several protocols [4]. Closure of the palate at the same time as the chéilorhinoplasty or closure of the palate before cheilorhinoplasty or closure of the palate after cheilorhinoplasty. Initial surgical repair of a cleft palate, called palatoplasty, does not always result in normal functioning of the palate. If the soft palate continues to function improperly, the patient may experience speech difficulties because of inability to control the air flow into the nose [25]. This problem may be diagnosed as velopharyngeal insufficiency, the inability to completely close the velopharyngeal sphincter during speech. To correct this condition, a secondary surgical procedure known as pharyngoplasty can be performed our study revealed only two patients who underwent pharyngoplasty. One at 15 years old and the other at 5 years old, Bicknell, et al. [25] found that the age of repair was not a significant factor. Other researchers have found significant differences with age at repair. Marrinan and others $[25,26]$ found that the earlier a cleft was repaired (8-10 months was the youngest group), the less likely the patient would need a pharyngeal flap. Also, the need for a pharyngeal flap increased with age at primary repair. However, Ysunza, et al. [25,27] found no significant difference in velopharyngeal insufficiency between patients undergoing primary repair at 6 months and those undergoing primary repair at 12 months [25]. Therefore, each team has a different approach when it comes to the global therapeutic calendar that will help the child affected by this malformation become, at the end of this growth, a normal child. In fact, a European survey carried out within the framework of the Eurocleft project counted 194 different therapeutic protocols for 201 centers listed. This confirmed the extreme diversity of technical choices and therapeutic calendars of the 11 French and Belgian teams [4]. Some repair the clefts back and forth starting with a neonatal repair of the lip and nose, so that primary rhinoplasty is performed between 5 and 10 days after birth. This cheilorhinoplasty is followed by a velopalatal intervention around 6th or 7th months [4]. Others with care to reduce the number of operating procedures perform a global repair in one or two steps, by helping the tightness of the palate [28]. Others still delay the closure of the bony palate to the age of 12 years.

The impact of CLP on the oral sphere is considerable and relate to essential functions such as hearing and phonation. In fact the incidence of otitis media with related mild to moderate hearing loss is high among children born with $\mathrm{CP}$, which may cause cognitive/ linguistic delays, and language/phonological disorders [29]. For most teams, speech follow-up should begin at an early age of associated with parental guidance, the treatment begins around the age of three and continues with regular phonetic assessments until puberty. The evaluation of phonation also makes it possible to decide whether or not indicate a secondary surgery. In our study population, $31.7 \%$ of patients received speech therapy. 


\section{Open Access Journal of Dental Sciences}

The age of treatment varies between 3 years and 36 years. While only $10.5 \%$ started their treatment at the age of 3 years which can be justified by the high cost of speech therapy. In general, Intervention can take place at any time but must be appropriate, timely and tailored to the individual [30].

Conventionally, the closure of the alveolar clefts takes place during a second operating phase [31]. Two major techniques that can be complementary bone grafting and gingivoperiosteoplasty are used.

Bone grafting: Cleft gaps are closed with alveolar bone grafts in surgical procedure called osteoplasty. Autogenic bone is taken from the iliac crest as the gold standard. The time of grafting can be divided into two stages: primary and secondary. The alveolar defect is usually reconstructed between 7 and 11 years and is often related to the development of the maxillary canine root [32]. In our study $11.7 \%$ of the population had a bone graft. The age of this intervention varies between 5 years and 30 years: $49.9 \%$ of patients performed this procedure between 5 and 8 years old whereas 28.4\% between 10 and 14 years old. Bone grafting is commonly performed in the protocol of many teams. Also at Showa University in Tokyo [33] performs the alveolar transplant at 5 years and the graft is taken from the iliac crest. Other schools postpone it after the eruption of permanent incisors and before the canine eruption [28]. According to Vlachos [34], bone grafting in temporary dentition can interfere with the vertical and horizontal development of the maxillary, yet if it is not grafted, it cannot be used as a bone support for the eruption of the canine.

Gingivoperiosteoplasty (GPP): It aims to restore the continuity of the attached gingiva, removes the soft tissue barrier within an alveolar cleft and replaces it with a gingivoperiosteal tunnel that facilitates bone healing through guided tissue regeneration (GTR) without the need for bone grafting and its associated donor site morbidity [35]. In our study only $4.2 \%$ had a gingivoperiosteoplasty at ages between 8 and 25 years old. According to HOOPER [35] GPP plays both an important and a controversial part in the cleft surgeon's mission to provide the best results in the least number of surgeries. Although it may normalize the form and function at infancy and avoid secondary alveolar bone grafting in mixed dentition, the technique has historically been associated with iatrogenic dento-facial restriction requiring more extensive orthodontic and orthognathic treatment at the age of skeletal maturity.
The early orthopedics consists of the placement of palatal plates, to close the cleft, thus facilitating feeding by restoring a separation between the respiratory tract and the digestive tract. These plates are either neutral or active [36]. In our study, $21.7 \%$ of patients had plate at birth. The use of palatal patches in babies is controversial. The Eurocleft project shows that half of the European teams use pre-surgical orthopedic treatment [4]. In our population only one patient $(0.8 \%)$ received an interceptive treatment in temporary dentition. Treatments in temporary dentition are the subject of controversy in the literature. If they are undertaken, as a general rule, the treatment should be short and punctual as further treatment will be necessary later. In general most authors differ the treatment to mixed dentition, such than Langlande and Lemasson [37]. 24.2\% of our study population had orthodontic treatment in mixed dentition at ages between 6 and 12 years. According to the majority of the authors, interception in mixed dentition is unavoidable. Indeed with the eruption of the permanent incisors, the appearance of the oral cavity is often degraded. In our study, $50 \%$ of patients with permanent dentition had orthodontic treatment alone, of which $26.7 \%$ had a treatment with premolar extraction.

Orthodontic treatment using fixed appliance is chosen in simple cases that do not present agenesis or anteroposterior discrepancy, if the sagittal dimensions has been well maintained, it is sufficient to align teeth the and obtain good occlusal relations. According to Lesne in case of dental disharmonia, extractions are necessary and depend on the length of the arch, the presence of agenesis or teeth Supernumerary and molar angle relationship [38].

In our study $50 \%$ of patients needed orthodonticsurgical treatment. In a patient with a cleft, the osteotomy is essentially maxillary advancement, but it can be bimaxillary in cases of vertical excess or mandibular prognathism [38]. $25 \%$ of our study population underwent secondary cheiloplasty which aimed correcting the abial defects. There are many types of defects: asymmetry of height, imperfection of the mucocutaneous line, mucous excess, scar unsightly [30]. Secondary cheiloplasty aims at restoring a flexible, symmetrical and free lip. Treatment can be undertaken as soon as there is a functional disorder or when the schoolaged child feels an embarrassment in front of the eye others $[39,40] .15 \%$ of our study population performed secondary rhinoplasty. Nasal defects are common, mainly septal deviation, nasal asymmetry and collapse of the nostril threshold in unilateral clefts, columellar shortening and asymmetry of the nasal alas in the 
bilateral clefts [30]. Secondary rhinoplasty is the last corrective surgery performed. It will be at the end of orthodontic and orthopedic treatment $[30,17]$.

In our study only $6 \%$ had treatments for phonatory sequelae. Palatal fistulas may appear in various places after primary treatment (by rupture of sutures, infection, hematoma) or during of orthodontic expansion. [17]. Spreistersbach quoted $50 \%$ of children with repaired cleft palate developed normal speech spontaneously, 25\% required speech and language therapy and $25 \%$ required further palatal surgery. However, Witzel reported that only $25 \%$ developed normal speech spontaneously and $75 \%$ required episodes of speech and language therapy throughout childhood and adolescence. In our study only $1.7 \%$ had a management of the phonatory sequelae.

Children with CLP are bound to encounter many psychological difficulties, these limitations tend to build up over a period of time, anxiety, depression, and palpitations were reported about twice as often by subjects with cleft lip and palate compared with controls, and these psychological problems were strongly associated with concerns about appearance, dentition, speech, and desire for further treatment $[41,14]$. These psychological effects are found in children but also in parents [30]. In our study only $3.3 \%$ of patients received a psychological attention, this paucity might be due to the cost of psychological therapy in Morocco which compromises the quality of life of these children and their families.

In the light of this work, and in order to facilitate the management of patients with cleft lip and palate by the orthodontist, we propose a protocol of care which results from the evaluation of what is done in our country in the field of health system dedicated to the patients carrying cleft lip and palate [42] (Table 6).

\begin{tabular}{|c|c|c|c|c|}
\hline Age At birth & Surgery & $\begin{array}{c}\text { Orthodontics Placement } \\
\text { of a Palatal plate }\end{array}$ & Dentistry & Phonology \\
\hline $\begin{array}{c}\text { During the first } \\
\text { months }\end{array}$ & $\begin{array}{c}\text { Primary lip repair, } \\
\text { rhinoplasty, veloplasty }\end{array}$ & $\begin{array}{c}\text { Pre /post-surgical } \\
\text { orthopaedic preparation }\end{array}$ & Information and advice & Post-surgical control \\
\hline 1-2 years & Temporary dentition: & $\begin{array}{c}\text { Surveillance and } \\
\text { screening } \\
\text { interception }\end{array}$ & $\begin{array}{c}\text { Velar function } \\
\text { monitoring }\end{array}$ \\
\hline 7-4 years & pecondary surgery of the \\
alveolar cleft & $\begin{array}{c}\text { Mixt dentition: } \\
\text { orthopaedic/orthodontic } \\
\text { treatment. Preparation for } \\
\text { secondary surgery }\end{array}$ & $\begin{array}{c}\text { Surveillance and } \\
\text { screening Dental care }\end{array}$ & $\begin{array}{c}\text { Velar function } \\
\text { monitoring, } \\
\text { Rehabilitation of } \\
\text { swallowing }\end{array}$ \\
\hline 14- 16 years & $\begin{array}{c}\text { Permanent dentition: } \\
\text { orthodontic treatment }\end{array}$ & $\begin{array}{c}\text { Surveillance and } \\
\text { screening Dental care }\end{array}$ & $\begin{array}{c}\text { Velar function } \\
\text { monitoring }\end{array}$ \\
\hline End of growth & $\begin{array}{c}\text { Orthognathic surgery, } \\
\text { Secondary surgeries of } \\
\text { labial, velar... sequelea }\end{array}$ & $\begin{array}{c}\text { Preparation for orthognatic } \\
\text { surgery, End of orthodontic } \\
\text { treatment Retention }\end{array}$ & $\begin{array}{c}\text { Prosthetic } \\
\text { rehabilitation }\end{array}$ & $\begin{array}{c}\text { Post-surgical evaluation } \\
\text { of the velar function }\end{array}$ \\
\hline
\end{tabular}

Table 6: protocol proposition for the management of patients with cleft lip and palate.

\section{Conclusion}

The management of patients with labio-alveolarpalatal clefts is complex, both from a multidisciplinary and orthodontic point of view. The lack of an international consensus does make it even more challenging for the orthodontist. The management of these complex cases requires the intervention of several specialists: a surgeon, an orthodontist, a speech therapist, an otolaryngologist, a pedodontist and a psychologist. According to our study, the management of patients with CLP is unsatisfactory, especially the management of secondary effects of clefts which compromises the improvement of the quality of life of these children and therefore compromises the intervention of the orthodontist. Strategies for better outcome for these children must be undertaken. As orthodontists, and in order to facilitate the intervention of the practitioner, we suggest the following recommendations:

a) Establish a global and orthodontic protocol for the management of children with facial clefts to reduce complications and to improve the quality of life of these children.

b) Inform parents of the length of the care process from birth to the end of growth. 


\section{Open Access Journal of Dental Sciences}

c) Initiate studies and research on the orthodontic management of patients with facial clefts.

d) Provide specific training for orthodontists in the field of care of children with clefts.

\section{References}

1. Olasoji HO, Hassan A, Adeyemo WL (2011) Survey of management of Children with Cleft Lip and palate in teaching and specialist hospitals in Nigeria. Cleft Palate Craniofacial J 48(2): 150-155.

2. Al-Bustan Sa, El-Zawahri Mm, Al-Adsani Am, Bang Rl, Ghunaim I, et al. (2002) Epidemiological and genetic study of 121 cases of oral clefts in Kuwait. Orthod Craniofac Res 5(3): 154-160.

3. Bhandari S, Soni BW, Saini SS (2018) From birth till palatoplasty: Prosthetic procedural limitations and safeguarding infants with palatal cleft. J Indian Soc Pedod Prev Dent 36(1): 101-105.

4. Martinot-Duquennoy V, Capon N (2002) Synthése de la prise en charge des fentes labiales et palatines par onze équipes francophones en 2001. Ann Chir Plast Esthét 47(2): 166-171.

5. Rakotoarison RA, Andrianony ER, Fanja LRA, Rabetrano AN, Ahmed F (2011) Étude des anomalies dentaires associées aux fentes labio-palatines: à propos d'un cas d'une série de 85 cas. Med Buccale Chir Buccale 17: 7-14.

6. Okan AM, Sehrazat E, Ozge U, Uflak TM (2010) Dental anomalies in individuals with cleft lip and/or palate. Eur J Orthodont 32(2): 207-213.

7. Abdurrazaq TO, Micheal AO, Lanre AW, Olugbenga OM, Akin LL (2013) Surgical outcome and complications following cleft lip and palate repair in a teaching hospital in Nigeria. Afr J Paediatr Surg 10(4): 345-357.

8. Tessier P (1976) Anatomical classification of facial, cranio-facial and latero- facial clefts. J Maxillofac Surg 4(2): 69-92.

9. Ugboko V, Owotade F, Otuyemi O, Adejuyigbe $\mathrm{O}$ (1997) Experience with cleft lip and palate patients seen in a Nigerian Teaching Hospital. Paed Dent J 7: 41-44.

10. Rival Jm, David A (2001) Génétiques des fentes labiopalatines. Rev Stomatol Chir Maxillofac 102(3-4): 171-181.
11. Croen L, Shaw G, Wasserman C, Tolarova M (1998) Racial and ethnic variations in the prevalence of orofacial clefts in California. Am J Med Genet 79(1): 42-47.

12. Peterson-Falzone S, Hardin-Jones M, Karnell M (2001) Cleft palate speech. $4^{\text {th }}$ (Edn.), Elsevier, St Louis: Mosby, pp: 43-67.

13. Sheldon WR (1999) Two unilateral complete cleft lip and palate orthodontic cases reated from birth to adolescence. Am J Orthod Dentofacial Orthop 115(1): 61-71.

14. Lai MC, King NM, Wong HM (2009) Abnormalities of maxillary anterior teeth in Chinese children with cleft lip and palate. Cleft Palate Craniofac J 46(1): 58-64.

15. Al Jamal Ga, Hazza'am, Rawashdeh Ma (2010) Prevalence of dental anomalies in a population of cleft lip and palate patients. Cleft Palate Craniofac J 47(4): 413-420.

16. Lucia Mm, Susana Mdr, Fabiane A, Diogo Av (2010) Characteristics and distribution of dental anomalies in a Brazilian cleft population. Rev Odonto stomat 25(2): 137-141.

17. Eigbobo JO, Akadiri OA (2011) Pattern of cleft lip and palate deformities and associated anomalies in a selected Nigerian population. NJPS 7(2): 59-64.

18. Tan ELY, Kuek MC, Wong HC, Ong SAK, Yow M (2018) Secondary Dentition Characteristics in Children With Nonsyndromic Unilateral Cleft Lip and Palate: A Retrospective Study. Cleft Palate Craniofacial J 55(4): 582-589.

19. Uchiyama T, Yamashita Y, Susami T, Kochi S, Suzuki S, et al. (2012) Primary treatment for cleft lip and/or cleft palate in children in Japan. Cleft Palate Craniofac J 49(3): 291-298.

20. Taub PJ, Piccolo P (2016) Cleft lip repair: Through the looking glass. J Craniofac Surg 27(8): 2031-2035.

21. Haddock NT, McRae MH, Cutting CB (2012) Longterm effect of primary cleft rhinoplasty on secondary cleft rhinoplasty in patients with unilateral cleft lipcleft palate. Plastic Reconstruc Surg 129(3): 740-748.

22. Thornton J, Nimer S, Howard P (1996) The incidence, classification, etiology, and embryology of oral clefts. Semin Orthod 2(3): 162-168. 


\section{Open Access Journal of Dental Sciences}

23. Schweckendiek W, Doz P (1978) Primary veloplasty: long-term results without maxillary deformity. a twenty-five year report. Cleft Palate J 15(3): 268-274.

24. Diah E, LO L, Yun C, Wang R, Wahyuni LK, et al. (2007) Cleft oronasal fistula: a review of treatment results and a surgical management algorithm proposal. Chang Gung Med J 30(6): 529-537.

25. Bicknell S, McFadden LR, Curran JB (2002) Frequency of pharyngoplasty after primary repair of cleft palate. J Can Dent Assoc 68(11): 688-692.

26. Marrinan EM, LaBrie RA, Mulliken JB (1998) Velopharyngeal function in nonsyndromic cleft palate: relevance of surgical technique, age at repair, and cleft type. Cleft Palate Craniofac J 35(2): 95-100.

27. Ysunza A, Pamplona MC, Medoza M, Garcia-Velasco M, Aguilar MP, et al. (1998) Speech outcome and maxillary growth in patients with unilateral complete cleft lip/palate operated on at 6 versus 12 months of age. Plast Reconstr Surg 102(3): 675-679.

28. Aknin JJ (2008) Le point sur les fentes labio-alvéolopalatines. Rev Orthop Dento Fac 42: 391-402.

29. Klintö K, Svensson H, Elander A, Lohmander A (2014) Speech and phonology in Swedish-speaking 3-yearsolds with unilateral complete cleft lip and palate following different methods for primary palatal surgery. Cleft Palate Craniofac J 51(3): 274-282.

30. Hodgkinson PD, Brown S, Duncan D, Grant C, McNaughton A, et al. (2005) Management of children with cleft lip and palate: a review describing the application of multidisciplinary team working in this condition based upon the experiences of a regional cleft lip and palate centre in the United Kingdom. Fetal Matern Med Rev 16(1): 1-27.

31. Jia YL, Fu MK, Ma L (2006) Long-term outcome of secondary alveolar bone grafting in patients with various types of cleft. Br J Oral Maxillofac Surg 44(4): 308-312.

32. Marko V, Knežević P, Jokić D, Jerko R, Domagoj Ž, et al. (2014) Alveolar Bone Grafting in Cleft Patients: from Bone Defect to Dental Implants. Acta stomatologica Croatica 48(4): 250-257.
33. Iwamoto T, Yoshizaki K, Sonoda A, Yuki N, Yumiko M, et al. (2009) Prevalence of natal/neonatal teeth in cleft lip and palate infants. Pediatric Dent J 19(1): 4651.

34. Christos MC (1996) Orthodontic treatment for the cleft palate patient. Seminars Orthodontics 2(3): 197204.

35. Hopper RA, Birgfield CB (2009) Gingivoperiosteoplast y. Comprehensive cleft care. McGraw Hill Medicine, New York.

36. Pedro Santiago E, Barry Grayson H (2009) Role of the craniofacial orthodontist on the craniofacial and cleft lip and palate team. Seminars in Orthodontics 15(4): 225-243.

37. Kawakami M, Yagi T, Takada K (2002) Maxillary expansion and protraction in correction of midface retrusion in a complete unilateral cleft lip and palate patient. Angle Orthod 72(4): 355-361.

38. Vargervik K (1983) Growth characteristics of the premaxilla and orthodontic treatment principles in bilateral cleft lip and palate. Cleft Palate J 20(4): 289302.

39. Thornton JB, Nimer S, Howard PS (1996) The incidence, classification, etiology, and embrylogy of oral clefts. Semin Orthod 2(3): 162-168.

40. Tindlund RS (1994) Skeletal response to maxillary protraction in patients with cleft lip and palate before age 10 years. Cleft Palate Craniofacial J 31(4): 295308.

41. De Sousa A, Devare S, Ghanshani J (2009) Psychological issues in cleft lip and cleft palate. J Indian Assoc Pediatr Surg 14(2): 55-58.

42. Ramstad T, Ottem E, Shaw WC (1995) Psychosocial adjustment in Norwegian adults who had undergone standardised treatment of complete cleft lip and palate. Part II. Self-reported problems and concerns with appearance. Scand J Plast Reconstr Surg Hand Surg 29(4): 329-336. 